\section{Evaluation of the change in accommodation amplitude in subjects with pseudoexfoliation}

\begin{abstract}
Purpose To evaluate the changes in accommodation amplitude in cases with pseudoexfoliation.

Materials and methods Twenty-nine eyes having pseudoexfoliation and 37 normal eyes aged between $40-60$ years were included in the study. After ophthalmic examination, accommodation amplitude was measured using Powerrefractor II. Besides, axial length, anterior chamber depth, and lens thickness was measured by A-scan ultrasonography. The results obtained were evaluated by independent samples' $t$-test.
\end{abstract}

Results There was no difference in mean age between cases with pseudoexfoliation and normal cases $(P=\mathbf{0 . 1 3 1})$. Mean accommodation amplitude was significantly lower in cases with pseudoexfoliation $(P=0.002)$. Axial length, anterior chamber depth, and lens thickness measurements did not show significant change between groups $(P=0.55$,

Department of

Ophthalmology, Afyon Kocatepe University School of Medicine,

Afyonkarahisar, Turkey

Correspondence: GF Yavas, P.K. 25,

Bahcelievler 06502, Ankara/Turkey

Tel: + 0090505 5044147;

Fax: + 00902722144776.

E-mail: gkumbar@

ttnet.net.tr

Received: 26 October 2007 Accepted in revised form: 15 April 2008

Published online: 23 May 2008
$P=0.66, P=0.36$, respectively).

Conclusion In the presence of pseudoexfoliation, ciliary apparatus can be decreased in earlier ages.

Eye (2009) 23, 822-826; doi:10.1038/eye.2008.143; published online 23 May 2008

Keywords: accommodation; pseudoexfoliation; ciliary apparatus

\section{Introduction}

Accommodation is the dynamic change of the refractive state of the eye by which the eye focuses on near objects. Though there are affected and accommodation amplitude can be
GF Yavas, F Öztürk, T Küsbeci, ÜÜ Inan, Ü Kaplan and SS Ermiş

different theories about accommodation, the widely accepted theory is the theory of Helmholtz. ${ }^{1,2}$ According to the theory of Helmholtz, ciliary muscle contracts and moves forward and inside, zonular fibres become relaxed and the lens become more spherical during accommodation. So, the diameter of the lens decreases, whereas the thickness of the lens increases and the depth of the anterior chamber and vitreous decreases during accommodation.

Human accommodation amplitude begins to decline progressively with age after the second decade of life. In human subjects, $2 / 3$ of the accommodation amplitude will be lost at 35 years, whereas it will be completely gone by the age of 50-55 years. ${ }^{1}$ So, the near point of the eye recedes towards the far point with age.

Although 1-1.5 D of accommodation remains in subjects older than 65 years, this is thought to be related with the depth of focus of the optical system. ${ }^{3}$ If the non-accommodating eye is accepted to be emmetropic, $2.5-4 \mathrm{D}$ of accommodation is required to image objects at 25-40 cm clearly. ${ }^{1}$ If the accommodation amplitude decreases below this, near objects will be blurred and subjects will have asthenopic complaints, which can be corrected by bifocal or reading spectacles. ${ }^{1}$

The most preferred method in the objective evaluation of accommodation amplitude is photorefraction. The principle of photorefraction has first been described by Howland and Howland ${ }^{4}$ in 1974 as the measurement of refractive state from a distance of $1 \mathrm{~m}$ or more. Powerrefractor is an automated infra-red videoretinoscope measuring dynamic accommodation based on the eccentric photorefraction technique. The Powerrefractor determines the refractions sequentially in the 
30-, 90-, 150-degree pupil meridians using a six-armed retinoscope with six such arrays. ${ }^{5}$ The most important limitation of Powerrefractor is the need of pupil diameter larger than $3 \mathrm{~mm}$.

Pseudoexfoliation (PEX) is a degenerative fibrillopathy characterized by pathologic production and accumulation of abnormal extracellular material in the anterior segment of the eye and extraocular tissues. ${ }^{6}$ In the eye, the abnormal extracellular material is produced by lens epithelium, non-pigmented ciliary epithelium, trabecular, corneal, and vascular endothelium, and all cell types of the iris. ${ }^{7}$ In eyes with PEX, the anterior and posterior lens capsule appears to be morphologically normal, whereas the pre-equatorial capsule (corresponding to the zone of zonular anchorage) is associated with marked alterations. ${ }^{8}$ The accumulation of PEX material around zonular fibres results in a disruption of the zonular apparatus. ${ }^{8,9}$

As zonular apparatus is affected in PEX syndrome, it is possible that accommodation amplitude can be affected in subjects with PEX. As we could not find a study evaluating this topic in the literature, we aimed to evaluate the changes in accommodative amplitude in subjects with PEX using powerrefractometer.

\section{Materials and methods}

The study was planned as a prospective study. Study group comprised 29 eyes with PEX and control group comprised right eyes of 37 normal subjects aged between 40-60 years. Both the subjects with PEX and control group were recruited from patients applying to our eye clinic for routine ophthalmic examination. If PEX was unilateral, the eye with PEX was taken into the study but if PEX was bilateral, the right eye was taken into the study. Subjects were divided into two age groups. Group 1 consisted of subjects aged between 40-49 years and group 2 consisted of subjects aged between 50-60 years. The study was approved by the institutional Ethics Committee and written informed consent was obtained from all patients.

Routine ophthalmic examination was performed to all cases. Best-uncorrected visual acuity was measured with Snellen chart and converted to logarithm of the minimum angle of resolution (logMAR). Intraocular pressure (IOP) was measured using applanation tonometer. In the PEX group, IOP measurement was repeated after 6 months for relative objective assessment of disease progression. Before dilatation, the iris and iris margins were evaluated for PEX deposits using slit-lamp assessment. After dilatation with tropicamide $1 \%$, anterior segment slit-lamp examination was performed and PEX was diagnosed as the presence of any typical white deposits on the anterior lens surface. Fundoscopic examination was performed with a $90 \mathrm{D}$ lens at the slit lamp. For preventing the affect of tropicamide on accommodation, subjects were told to come 3 days later for accommodation and biometric measurements.

Exclusion criteria for all subjects were a Snellen visual acuity lower than 0.8; any ocular pathology except PEX such as glaucoma, uveitis, retinal detachment, amblyopia, or strabismus; a history of ocular trauma; previous intraocular surgery; a pupil diameter smaller than $3 \mathrm{~mm}$; a history of any topical drug use in the last 3 months; and any systemic disease that could affect the eye like diabetes mellitus or hypertension.

Accommodation amplitude was measured by infra-red photorefractor (Powerrefractor II, PlusOptix, Nürnberg, Germany). The subjects were told to sit at $1 \mathrm{~m}$ distance from the Powerrefractor. The subjects used a chin rest to limit head movements at minimal. Room lighting was reduced to have the pupils larger. The pupil diameter was recorded automatically by the Powerrefractor. The Powerrefractor was adjusted according to the fixation axis and the measurement was performed without pupil dilatation. The subject was first told to look at a distant target $3 \mathrm{~m}$ away from the subject at the midline and than to look at an accommodative target $30 \mathrm{~cm}$ away from the subject at the midline. By having the subject fixate at a distant target first and a near target thereafter, we aimed to prevent the dioptric change that can occur during disaccommodation, which has larger amplitude than accommodation. The dioptric difference between distant refraction and near refraction was recorded as accommodation amplitude. The measurement was repeated three times and the mean of these measurements was calculated for statistical evaluation. Ocular movement was controlled by the gaze tracker automatically and measurement was repeated when there was eccentric eye movement (fixation was determined to be central, if fixation was within 10 degrees horizontal and 5 degrees vertical).

Biometric measurements were performed to all subjects. Axial length, anterior chamber depth, and lens thickness of all subjects were measured by A-scan ultrasonography (E-Z Scan AB 5500, Sonomed, USA). The measurements were repeated three times and the mean was calculated for statistical evaluation. Subjects were told to look at a distant target $3 \mathrm{~m}$ away. Axial length was defined as the distance between anterior corneal surface and the retina along the optical axis. Anterior chamber depth was defined as the distance between the posterior corneal surface and the anterior lens capsule along the optical axis. Lens thickness was defined as the distance between the anterior lens capsule and the posterior lens capsule along the optical axis.

Statistical analysis was performed using SPSS package program version 10.0. Sex distribution between groups 
was computed by $\chi^{2}$ test. All variables were tested for normality using the Shapiro-Wilk test. The significance of the differences for mean age, visual acuity, mean IOP, mean accommodation amplitude, mean pupil diameter, axial length, anterior chamber depth, and lens thickness between subjects with PEX and normal cases was determined with (a) independent samples' $t$-test for the variables with a normal distribution, (b) Mann-Whitney $U$-test for the variables found deviate significantly from normal distribution. The correlation between pupil diameter and accommodation amplitude for both PEX subjects and control group was evaluated by Pearson correlation test. For all times, $P$-values lower than 0.05 were determined to be significant.

\section{Results}

Mean age was $52.43 \pm 6.8$ years in subjects with PEX and $53.89 \pm 3.3$ years in control group $(P=0.131$, independent samples' $t$-test). Sex distribution is given in Table 1 . There was no difference in sex distribution between groups $(P=0.124)$. Snellen visual acuity was $0.95 \pm 0.01$ in subjects with PEX and $0.98 \pm 0.01$ in control subjects ( $P=0.074$, Mann-Whitney $U$-test $), \log$ MAR visual acuities were $0.02 \pm 0.01$ in subjects with PEX and $0.01 \pm 0.01$ in control subjects $(P=0.074$, Mann-Whitney $U$-test). Anterior segment examination and fundus examination were normal in all subjects except PEX in study group. Biometric measurement results are given in Table 2. Mean IOP was $15.30 \pm 2.8 \mathrm{mmHg}$ in control group and $14.37 \pm 2.6 \mathrm{mmHg}$ in PEX subjects $(P=0.17$, Mann-Whitney $U$-test). After 6 months, none of the PEX subjects developed glaucoma and mean IOP was still within normal limits $(14.57 \pm 2.5 \mathrm{mmHg})$ in subjects with PEX $(P=0.76$, independent samples $t$-test $)$.

Table 1 Sex distribution

\begin{tabular}{lccc}
\hline PEX & Women (no. \%) & Men (no. \%) & Total (no. \%) \\
\hline- & $23(63.9)$ & $14(46.7)$ & $37(56.1)$ \\
+ & $13(36.1)$ & $16(53.3)$ & $29(43.9)$ \\
\hline
\end{tabular}

$\mathrm{PEX}=$ pseudoexfoliation .
Mean accommodation amplitude was $1.07 \pm 0.6 \mathrm{D}$ (0.28 D-2.89D) in subjects with PEX and 1.66 $\pm 0.8 \mathrm{D}$ (0.30 D-3.53 D) in control group ( $P=0.002$, MannWhitney $U$-test). Mean accommodation amplitude was $1.45 \pm 0.77 \mathrm{D}$ in female subjects and $1.34 \pm 0.76 \mathrm{D}$ in male subjects $(P=0.48$, Mann-Whitney $U$-test).

In both sex groups, mean accommodation amplitude was significantly lower in subjects with PEX (for female subjects $P=0.023$, independent samples' $t$-test; for male subjects $P=0.029$, Mann-Whitney $U$-test) (Table 3).

Mean accommodation amplitude was significantly lower in patients over 50 years. Mean accommodation amplitude was $1.80 \pm 0.85 \mathrm{D}$ in group $1(40-49$ years $)$ and $1.24 \pm 0.67 \mathrm{D}$ in group 2 (50-60 years) $(P=0.010$, MannWhitney $U$-test). In group 1 , accommodation amplitude was significantly lower in subjects with PEX compared to control group, whereas in group 2 , the change in accommodation amplitude was not significant in subjects with PEX and control group (Table 4). In PEX subjects, though mean accommodation amplitude was lower in age group 1, the difference was statistically not significant, whereas in control subjects, accommodation amplitude declined significantly with age $(P=0.35$, independent samples' $t$-test; $P=0.038$, Mann-Whitney $U$-test, respectively).

Mean pupil diameter was $4.06 \pm 0.7 \mathrm{~mm}$ in women, whereas it was $3.76 \pm 0.6 \mathrm{~mm}$ in men $(P=0.052$, MannWhitney $U$-test). The pupil diameter was $4.11 \pm 0.7 \mathrm{~mm}$ in the first age group compared to $3.86 \pm 0.7 \mathrm{~mm}$ in group 2 $(P=0.18$, Mann-Whitney $U$-test). In group 1 , pupil diameter was $4.2 \pm 0.6 \mathrm{~mm}$ in women and $3.88 \pm 0.8 \mathrm{~mm}$ in men ( $P=0.36$, independent samples' $t$-test). In group 2 , pupil diameter was $3.98 \pm 0.7 \mathrm{~mm}$ in women and $3.74 \pm 0.6 \mathrm{~mm}$ in men $(P=0.19$, Mann-Whitney $U$-test $)$. Mean pupil diameter was $3.96 \pm 0.7 \mathrm{~mm}$ in subjects with PEX and $3.90 \pm 0.7$ in control group $(P=0.89$, MannWhitney $U$-test). We could not find a correlation between pupil diameter and accommodation amplitude in our subjects $(P=0.91, r=0.014)$. There was no correlation between pupil diameter and accommodation amplitude both for subjects with PEX and for control group (for PEX subjects $P=0.60, r=-0.102$; for control group $P=0.54$, $r=0.105)$.

Table 2 Biometric measurement results

\begin{tabular}{lrrr}
\hline Biometric parameter & $P E X+(\mathrm{n}=29)$ & $P E X-(\mathrm{n}=37)$ & $P$ \\
\hline Axial length $(\mathrm{mm})$ & $22.98 \pm 1.4$ & $23.24 \pm 1.4$ & $0.55^{\mathrm{a}}$ \\
Anterior chamber depth $(\mathrm{mm})$ & $1.34 \pm 0.6$ & $1.42 \pm 0.4$ & $0.25^{\mathrm{b}}$ \\
Lens thickness $(\mathrm{mm})$ & $3.54 \pm 0.4$ & $3.53 \pm 0.4$ & $0.36^{\mathrm{a}}$ \\
\hline
\end{tabular}

PEX = pseudoexfoliation.

'Independent samples' $t$-test;

'Mann-Whitney $U$-test. 
Table 3 Accommodation amplitude by pseudoexfoliation and gender

\begin{tabular}{lcc}
\hline PEX & \multicolumn{2}{c}{ Accommodation amplitude (dioptre) } \\
\cline { 2 - 3 } & Women $(\mathrm{n}=36)$ & Men $(\mathrm{n}=30)$ \\
\hline+ & $1.05 \pm 0.5$ & $1.09 \pm 0.7$ \\
- & $1.66 \pm 0.8$ & $1.64 \pm 0.7$ \\
$P$ & $0.023^{\mathrm{a}}$ & $0.029^{\mathrm{b}}$ \\
\hline
\end{tabular}

${ }^{a}$ Independent samples $t$-test;

${ }^{\mathrm{b}}$ Mann-Whitney $U$-test.

Table 4 Accommodation amplitude by pseudoexfoliation and age

\begin{tabular}{lcccc}
\hline Age group & & \multicolumn{2}{c}{ Accommodation amplitude (dioptre) } & \\
\cline { 3 - 4 } & $\mathrm{n}$ & PEX + & PEX- & $\mathrm{P}$ \\
\hline $\begin{array}{l}\text { Group 1 } \\
\text { (40-49 years) }\end{array}$ & 19 & $0.67 \pm 0.5$ & $1.94 \pm 0.8$ & 0.041 \\
$\begin{array}{l}\text { Group 2 } \\
\text { (50-60 years) }\end{array}$ & 47 & $1.10 \pm 0.6$ & $1.42 \pm 0.7$ & 0.11 \\
\hline
\end{tabular}

$\mathrm{P}=$ independent samples $t$-test; $\mathrm{PEX}=$ pseudoexfoliation.

\section{Discussion}

It is known that accommodation amplitude declines with age. ${ }^{10}$ Mordi and Ciuffreda ${ }^{11}$ evaluated accommodation in normal subjects aged between $21-50$ years and reported that mean accommodation velocity/amplitude did not differ with age but the latency increased. PEX is a systemic condition known to show an age-related increase. ${ }^{12,13}$ PEX can be seen in up to $30 \%$ of people aged over 60 years. ${ }^{14}$ Pavlin et $a l^{15}$ showed that patients with PEX showed prominent zonular remnants attached to the lens capsule and concluded that the weakness of the lens capsule at the periphery or midzonule in subjects with PEX could be related with these remnants. In our study, we evaluated accommodation amplitude in subjects aged between 40-60 years. Ideally, the evaluation of accommodation amplitude in PEX should be performed on younger subjects. However, as PEX is an age-related disease, the opportunity to assess the significance of these results in pre-presbyopic PEX subjects is vanishingly small. So, we did not include subjects aged 60 years or more, though PEX prevalence increases in subjects over 60 years.

In our study, accommodation amplitude was found to be significantly lower in subjects with PEX $(P=0.002)$. Similarly, accommodation amplitude was significantly lower in the second age group (50-60 years) compared to the first age group (40-49 years; $P=0.005$ ).

Accommodation amplitude showed no significant change between the age groups in subjects with PEX $(P=0.35)$, whereas accommodation amplitude decreased significantly in control group $(P=0.038)$. In both age groups, accommodation amplitude was significantly lower in subjects with PEX, though this difference was statistically significant only in the first age group. This shows that accommodation amplitude has been affected in the younger age group with PEX. It is known that with increasing age, age-related changes are seen in ciliary apparatus, zonular fibres, and lens capsule, lens elasticity decreases, lens thickness and stiffness increases, ability to disaccommodate decreases and ciliary muscle remodelling decreases independent of PEX.,16-20 In our opinion, the reason why PEX did not affect accommodation amplitude in the second age group is that as age-related changes have already been happened in ciliary apparatus, zonular fibres and lens capsule in this age group, and the measured accommodation amplitude in this group is not active accommodation, and tonic accommodation is independent from lens elasticity, zonular fibres, and ciliary muscle. So, accommodation amplitude declined significantly only in group 1 in which active accommodation is still present with a small amount. We found that gender did not affect accommodation amplitude $(P=0.54)$ and accommodation amplitude decreased significantly in subjects with PEX both in female subjects and male subjects (for female subjects $P=0.023$, for male subjects $P=0.041)$.

Axial length, anterior chamber depth, and lens thickness did not show any significant difference between subjects with PEX and control group. Though we found that pupil size was smaller in older subjects and in men, it was statistically not significant. Pupil diameter is known to be effective in accommodation amplitude; miosis causes an increase in the depth of focus and an increase in the measured accommodation amplitude. ${ }^{1,21}$ It has been shown that miosis occurs with increasing age. ${ }^{22}$ Winn et $a l^{23}$ measured pupil diameters of 91 normal subjects aged between 17-83 years and reported that pupil size decreased $0.015-0.043 \mathrm{~mm}$ each year related with the luminance level and pupil size was found to be independent of gender. Similarly, Jones ${ }^{24}$ reported that pupil diameter did not differ between men and women. We could not find any correlation between pupil diameter and accommodation amplitude in both PEX subjects and control group.

As a result, accommodation amplitude can be affected in subjects with PEX independent of gender. It will be reasonable to be careful about accommodation deficiency and related clinical conditions in young subjects with PEX.

\section{Acknowledgements}

This study was supported by the Afyonkarahisar Kocatepe University, Turkey. 


\section{References}

1 Glasser A, Kaufman PL. Accommodation and Presbyopia. In: Kaufman PL, Alm A (eds). Adler's Physiology of the Eye. St Louis: Mosby, 2002, pp 197-233.

2 Ludwig K, Wegschneider E, Hoops JP, Kampik A. In vivo imaging of the human zonular apparatus with highresolution ultrasound biomicroscopy. Graefes Ach Clin Exp Ophthalmol 1999; 237: 361-371.

3 Koretz JF, Kaufman PL, Neider NW, Goeckner PA. Accommodation and presbiopia in the human eye: aging of the anterior segment. Vision Res 1989; 29: 1685-1692.

4 Howland HC, Howland B. Photorefraction: a technique for study of refractive state at a distance. J Opt Soc Am 1974; 64: 240-249.

5 Gekeler F, Shaeffel F, Howland HC, Wattam-Bell J. Measurement of astigmatism by automated infrared photorefraction. Optom Vis Sci 2000; 77: 537-548.

6 Schlötzer-Schrehardt U, Naumann OH. Ocular and systemic pseudoexfoliation syndrome. Am J Ophthalmol 2006; 141: 921-937.

7 Naumann GOH, Schlötzer-Schrehardt U, Küchle M. Pseudoexfoliation syndrome for the comprehensive ophthalmologist: intraocular and systemic manifestations. Ophthalmology 1998; 105: 951-968.

8 Bourge JL, Robert AM, Robert L, Renard G. Zonular fibers, multimolecular composition as related to function (elasticity) and pathology. Pathol Biol 2007; 55: 347-359.

9 Garner A, Alexander RA. Pseudoexfoliative disease: histochemical evidence of an affinity with zonular fibers. Br J Ophthalmol 1984; 68: 574-580.

10 Neider MW, Crawford K, Kaufman PL, Bito LZ. In vivo videography of the rhesus monkey accommodative apparatus. Age-related loss of ciliary muscle response to central stimulation. Arch Ophthalmol 1990; 108: 69-74.

11 Mordi JA, Ciuffreda KJ. Dynamic aspects of accommodation: age and presbyopia. Vision Res 2004; 44: 591-601.
12 Krishnadas R, Nirmalan PK, Ramakrishnan R, Thulasiraj RD, Katz J, Tielsch JM et al. Pseudoexfoliation in a rural population of southern India: The Aravind comprehensive eye survey. Am J Ophthalmol 2003; 135: 830-837.

13 McCarty CA, Taylor HR. Pseudoexfoliation syndrome in Australian adults. Am J Ophthalmol 2000; 129: 629-633.

14 Ritch R, Schlötzer-Schrehardt U. Exfoliation syndrome. Surv Ophthalmol 2001; 45: 265-315.

15 Pavlin CJ, Buys YM, Pathmanathan T. Imaging zonular abnormalities using ultrasound biomicroscopy. Arch Ophthalmol 1998; 116: 854-857.

16 Strenk SA, Strenk LM, Semmlow JL, DeMarco JK. Magnetic resonance imaging study of the effects of age and accommodation on the human lens cross-sectional area. Invest Ophthalmol Vis Sci 2004; 45: 539-545.

17 Fischer RF. Presbiopia and changes with age in the human crystalline lens. J Physiol 1973; 228: 765-779.

18 Croft MA, Kaufman PL, Crawford KS, Neider MW, Glasser A, Bito LZ. Accommodation dynamics in aging rhesus monkeys. Am J Physiol 1998; 275: 1885-1897.

19 Fisher RF. Elastic constants of the human lens capsule. J Physiol 1969; 201: 1-19.

20 Fisher RF. The significance of the shape of the lens and capsular energy changes in accommodation. J Physiol 1969; 201: 21-47.

21 Winn B, Pugh JR, Gilmartin B, Owens H. The effect of pupil size on static and dynamic measurements of accommodation using an infrared optometer. Ophthalmic Physiol Opt 1989; 9: 277-283.

22 Fotiou DF, Brozou CG, Tsiptsios DJ, Fotiou A, Kabitsi A, Nakou $\mathrm{M}$ et al. Effect of age on pupillary light reflex: evaluation of pupil mobility for clinical practice and research. Electromyogr Clin Neurophysiol 2007; 47: 11-22.

23 Winn B, Whitaker D, Elliott DB, Phillips NJ. Factors affecting light adapted pupil size in normal human subjects. Invest Ophthalmol Vis Sci 1994; 35: 1132-1137.

24 Jones R. Do women and myopes have larger pupils? Invest Ophthalmol Vis Sci 1990; 31: 1413-1415. 